\title{
First Report of Puccinia coronata var. coronata sensu stricto Infecting Alder Buckthorn in the United States
}

\begin{abstract}
Shawn C. Kenaley, School of Integrative Plant Science, Plant Pathology and Plant-Microbe Biology Section, Cornell University, Ithaca, NY 14853; Geoffrey Ecker, Department of Biological Sciences, Arkansas Tech University, Russellville, AR 72801; and Gary C. Bergstrom, School of Integrative Plant Science, Plant Pathology and Plant-Microbe Biology Section, Cornell University, Ithaca, NY 14853
\end{abstract}

Accepted for publication 28 March 2017.

Crown rust, caused by Puccinia coronata sensu lato, is one of the most common and economically important diseases of cultivated oat (Avena sativa), forage grasses, and turf grasses worldwide (Simons 1985). Recent phylogenetic analyses have demonstrated that $P$. coronata is a species complex consisting of seven species wherein $P$. coronata sensu stricto presently is divided into two varieties ( $P$. coronata var. coronata and var. avenae) with $P$. coronata var. avenae further separated to include two formae speciales (f. sp. avenae and f. sp. graminicola; (Liu and Hambleton 2013; Szabo 2006). Primary hosts of $P$. coronata var. avenae f. sp. avenae include taxa in at least nine genera in Poaceae, such as oat, Festuca (fescue); Hordeum (barley); Glyceria (mannagrass); and Lolium (ryegrass); whereas f. sp. graminicola is a principal parasite of taxa in the genus Arrehnatherum (oat grass), Glyceria, and Holcus (velvetgrass). The latter formae speciales share an aecial host, common buckthorn (Rhamnus cathartica) — an introduced species from Eurasia with epidemiological importance in the development of crown rust in North America (Simons 1985). In contrast to P. coronata var. avenae, $P$. coronata var. coronata s.s. is found almost exclusively in Europe (Liu and Hambleton 2013) and host-alternates between alder buckthorn (Frangula alnus) and rock buckthorn ( $R$. saxatatilis) to grasses in at least two genera, Agrostis (bentgrass) and Calamagrostis (reed grass). Alder buckthorn and known telial hosts of $P$. coronata var. coronata-Agrostis stolonifera (creeping bentgrass), C. arundinacea (feather reed grass), and $C$. epigejos (chee reed) - have been accidentally and/or purposely introduced into the United States and elsewhere in North America.

In June 2016, we observed numerous aecia on the adaxial leaf surface of two alder buckthorns, Frangula alnus typica and F. alnus 'Fine Line' (Fig. 1); each at separate locations in Storrs, CT $\left(41.813670^{\circ} \mathrm{N},-72.251669^{\circ} \mathrm{W}\right.$; and $41.813519^{\circ} \mathrm{N},-72.249755^{\circ}$ $\mathrm{W}$, respectively). According to host distribution (Farr and Rossman 2017) and morphological examination of aecia and aeciospores (Kenaley et al. 2016), the rust fungus was identified as $P$. coronata s.l. Aecia ( $n=4$, two per collection) were cupulate and hypophyllous while aeciospores $(n=50$ spores per aecium, 200 total $)$ were globoid to broadly ellipsoid, finely verrucose, averaged $20.8( \pm 0.4) \times 16.7$ $( \pm 0.3) \mu \mathrm{m}$, and possessed hyaline walls that averaged $1.4( \pm 0.0) \mu \mathrm{m}$ thick. The specific identity of the rust fungus was further delimited by PCR amplification and sequencing of the internal transcribed spacer (ITS) region (Kenaley et al. 2016) as well as a partial sequence of the RNA Polymerase II subunit (RPB2) gene (Liu and Hambleton 2013). ITS and RPB2 data were subjected to separate BLASTn searches and, by gene region, integrated into three datasets: (i) ITS nearest matches in

Corresponding author: S. C. Kenaley; E-mail: sck26@cornell.edu

(C) 2017 The American Phytopathological Society

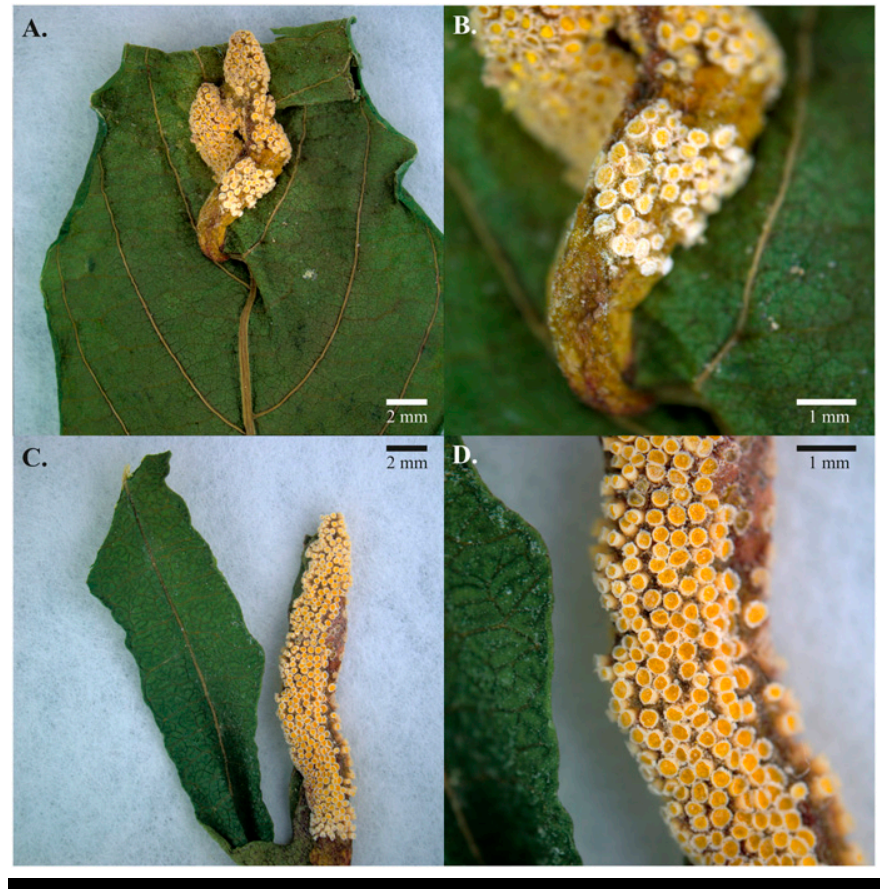

FIGURE 1

Aecia on the adaxial leaf surface of alder buckthorn, Frangula alnus typica (A and B) and F. alnus 'Fine Line' (C and D).

GenBank; (ii) ITS-P. coronata s.l. (Szabo 2006); and (iii) RPB2P. coronata s.l. (Liu and Hambleton 2013). Datasets were then subjected to maximum likelihood (ML) and parsimony analyses using PAUP* v. 4.0b10 (Swofford 2003). Consensus trees, data matrices, and PAUP blocks for the ML and MP analyses were deposited in TreeBASE (Study S20727). Voucher specimens for and DNA sequences from the aforementioned collections were deposited at the Arkansas Tech Univ. Herbarium (APCR) and in GenBank, respectively.

The nucleotide identities by gene region for ITS (GenBank Accession Nos. KY426916 and KY426917) and RPB2 (KY436234 and KY436235) sequences were identical between collections. BLASTn results revealed $99 \%$ and $100 \%$ nucleotide identity with $P$. coronata on oat grass (DQ355443) from the Czech Republic and P. coronata var. coronata on alder buckthorn (HM147367) from Sweden, respectively. Phylogenetic analyses utilizing ITS sequence data clearly demonstrated that the rust fungus infecting alder buckthorn in Connecticut is $P$. coronata s.s. (Fig. 2), sharing a most recent common ancestor with $\mathrm{f}$. spp. of $P$. coronata var. avenae. Moreover, according to analyses of the RPB2 gene, the infraspecific identity of the rust 
A ITS neareast matches in GenBank

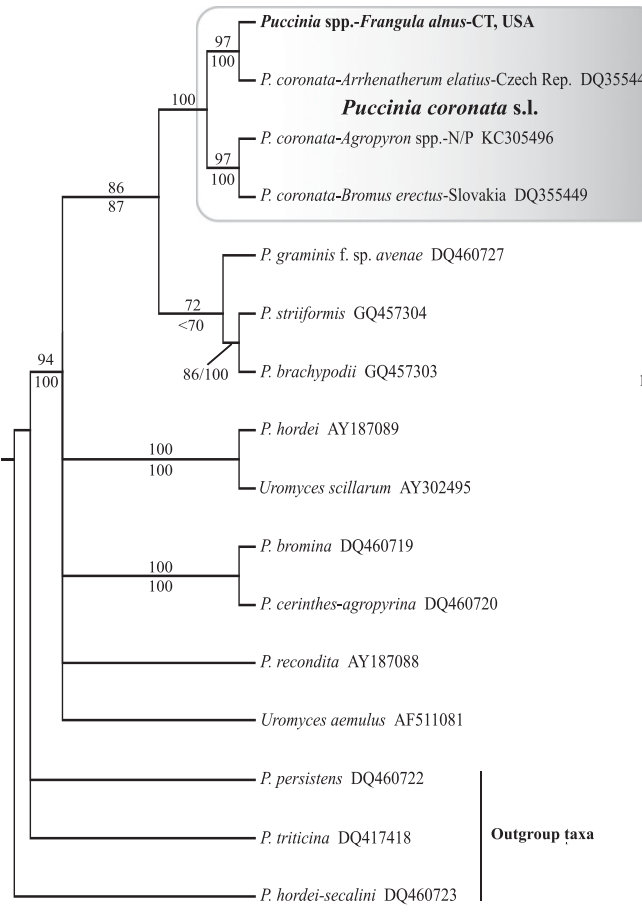

Model of sequence evolution: general time reversible plus gamma distributed rate variation among sites $(\mathrm{GTR}+\mathrm{G})$
B ITS-Puccinia coronata s.l. (Szabo 2006)

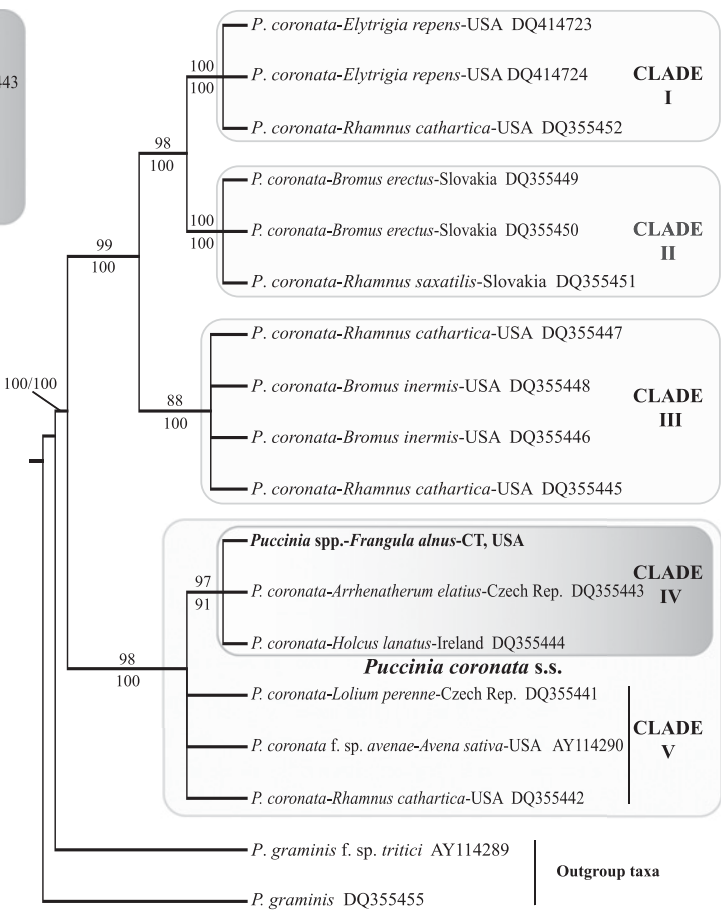

Model of sequence evolution: transition 2 plus gamma distributed rate variation among sites (TIM2+G)

\section{FIGURE 2}

Majority-rule consensus trees reconstructed using maximum likelihood (ML) and maximum parsimony (MP) approaches: (A) ITS nearest matches in GenBank and (B) ITS-Puccinia coronata s.l. (Szabo 2006). Numbers above and below branches indicate ML and MP bootstrap values (1000 replicates), respectively.

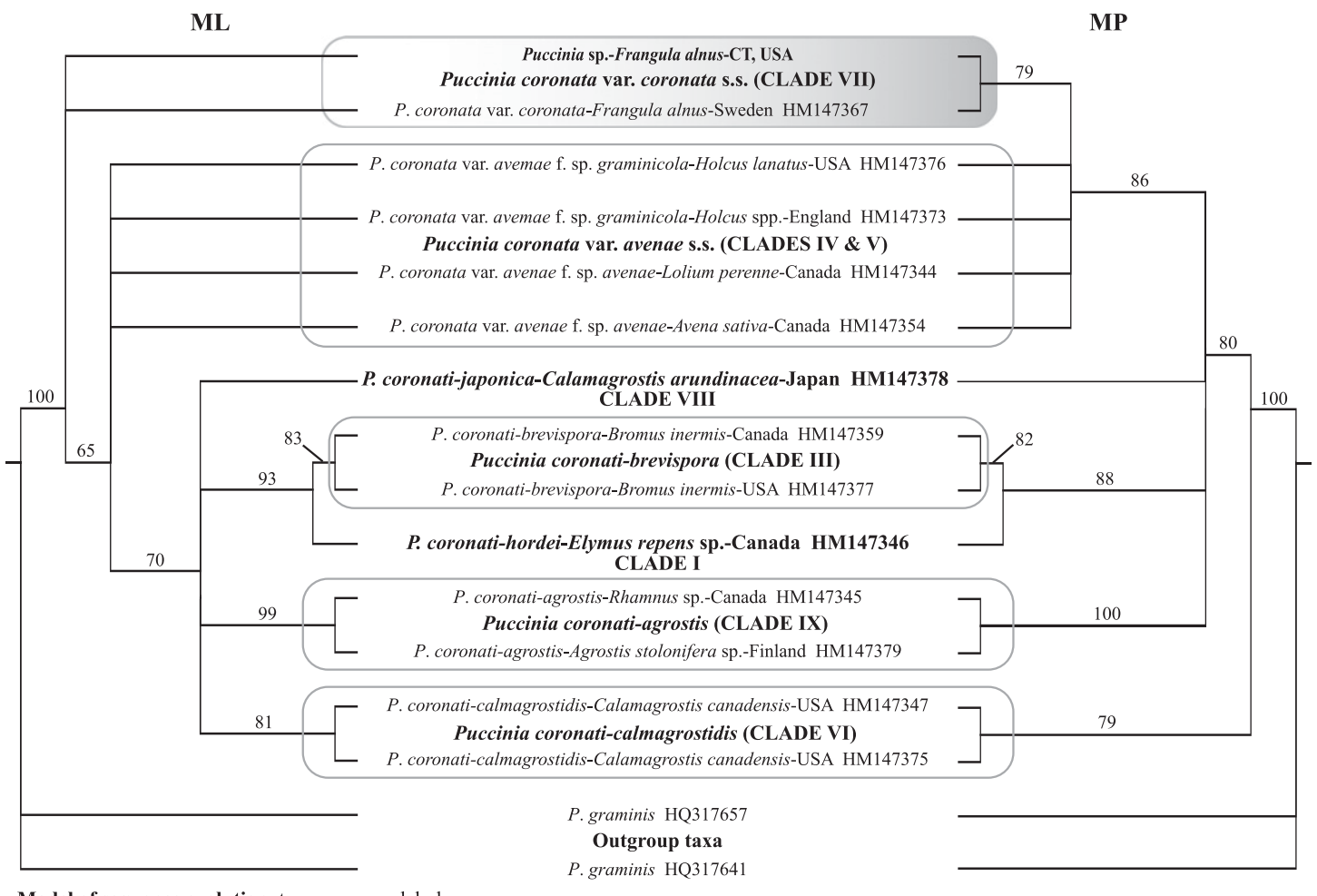

Model of sequence evolution: transverse model plus gamma distributed rate variation among sites $(\mathrm{TVMef}+\mathrm{G})$

\section{FIGURE 3}

Majority-rule consensus tree based on a 306 nucleotide partial sequence of the RPB2 gene region inferred from maximum likelihood (ML) and maximum parsimony (MP) analyses. Clades represent those designated by Liu and Hambleton (2013). Numbers above and below branches indicate ML and MP bootstrap values (1000 replicates), respectively. 
fungus was further delineated to $P$. coronata var. coronata (Fig. 3). To our knowledge, this is the first report and confirmation of $P$. coronata var. coronata s.s. in the United States. Additional collections from purported aecial and telial hosts of $P$. coronata var. coronata s.s. are necessary to determine its host range, geographic distribution, and incidence within the United States and elsewhere in North America.

\section{Literature Cited}

Farr, D. F., and Rossman, A. Y. 2017. Fungal Databases. U.S. National Fungus Collections, ARS, USDA, Beltsville, MD. Retrieved April 7, 2017, from https://nt.ars-grin.gov/fungaldatabases/
Kenaley, S. C., Hudler, G. W., and Bergstrom, G. C. 2016. Detection and phylogenetic relationships of Puccinia emaculata and Uromyces graminicola (Pucciniales) on switchgrass in New York State using rDNA sequence information. Fungal Biol. 120:791-806.

Liu, M., and Hambleton, S. 2013. Laying the foundation for a taxonomic review of Puccinia coronata s.l. in a phylogenetic context. Mycol. Prog. 12:63-89.

Simons, M. D. 1985. Crown rust. Pages 131-172 in: The Cereal Rusts (Vol. 2): Diseases, Distribution, Epidemiology, and Control. A. P. Roelfs and W. R. Bushnell, eds. Academic Press, Inc., Orlando, FL.

Swofford, D. L. 2003. Phylogenetic analysis using Parimony (*and other methods) Version 4. Sinauer Associates, Sunderland, MA.

Szabo, L. J. 2006. Deciphering species complexes: Puccinia andropogonis and Puccinia coronata, examples of differing modes of speciation. Mycoscience 47:130-136. 